\title{
RANCANG BANGUN SISTEM MANAJEMEN PENGETAHUAN UBI JALAR BERBASIS WEB MENGGUNAKAN METODE KMSLC
}

\author{
Surianti ${ }^{1}$, Nur Ain Banyal ${ }^{2}$, Syari Rukmana Wahab ${ }^{3}$ \\ ${ }^{1}$ surianti12p@gmail.com, 2mamafira16@gmail.com, 3Ay.rukmana@gmail.com \\ ${ }^{123}$ AMIK UMEL Mandiri Jayapura
}

\begin{abstract}
Abstrak
Penelitian ini merupakan penerapan sistem manajemen pengetahuan yang dapat digunakan para petani ubi jalar maupun masyarakat luas yang membutuhkan informasi dan pengetahuan tentang budidaya ubi jalar. Kurangnya informasi dan pengetahuan yang petani dapatkan tentang cara budidaya ubi jalar yang baik dapatkan menurunkan tingkat produksi. Sistem ini diharapkan dapat membantu para petani ubi jalar dalam mencari dan mendapatkan pengetahuan. Tujuan dari penelitian ini untuk mengembangkan suatu sistem manajemen pengetahuan berbasis web dalam mengolah pengetahuan. Adapun metode yang digunakan yaitu metode knowledge management system life cycle (KMSLC). Hasil dari penelitian ini dapat mendownload pengetahuan sehingga diharapkan dapat membantu penyuluh dalam transfer pengetahuan ke petani dan memudahkan petani untuk memperoleh pengetahuan mengenai budidaya ubi jalar yang tepat.
\end{abstract}

Kata kunci : KMSLC, Sistem Manajemen Pengetahuan, Ubi Jalar, web.

\section{Pendahuluan}

Kabupaten Keerom Provinsi Papua secara geografis berbatasan langsung dan berada memanjang di Daerah perbatasan Republik Indonesia dengan Negara Papua New Guinea (PNG) memiliki luas $9.365 \mathrm{Km}^{2}$, sementara itu suhu yang berkisar antara $25,0^{\circ} \mathrm{C}-32,2^{\circ} \mathrm{C}$, menjadikan Kabupaten Keerom memiliki suhu yang cukup panas dengan kelembaban yang cukup tinggi $(78,0 \%-$ $83,0 \%$ ). Panasnya suhu di Kabupaten Keerom diimbangi dengan curah hujan yang cukup tinggi sebesar $2.557 \mathrm{~mm}$ dan kecepatan maksimum angin berkisar antara 8,9 - 0,8 knot, sedangkan tekanan udara antara 1.009,7 mbps - 1.012,1 mbps. Sehingga Kabupaten Keerom sangat cocok untuk sektor pertanian khususnya budidaya ubi jalar [1]. Ubi jalar merupakan salah satu diversifikasi pangan yang sangat efisien karena seluruh bagian dari tanaman ini dapat diolah dan dimanfaatkan. Umbi dari ubi jalar dapat diolah menjadi berbagai macam makanan seperti keripik, chips, tepung, mie, snack, permen. Batang dan daun ubi jalar dapat dijadikan bahan pakan ternak dan bahan baku Industri. Selain itu, ubi jalar memiliki kandungan kalori yang tinggi sebesar $215 \mathrm{kal} / \mathrm{ha} / \mathrm{hari}$, berbeda dengan padi hanya sebesar $176 \mathrm{kal} / \mathrm{ha} / \mathrm{hari}$ dan jagung yang hanya $110 \mathrm{kal} / \mathrm{ha} / \mathrm{hari}$ [2]. Pada beberapa lokasi Pertanian di Kabupaten Keerom masih dilakukan dengan sistem tradisional sehingga tingkat produktifitasnya masih rendah. Kurangnya pengetahuan petani mengenai cara budidaya ubi jalar dengan benar sehingga menyebabkan semakin menurunnya produktivitas ubi jalar dalam Negeri. Untuk mengatasi permasalahan tersebut diperlukan berbagai upaya untuk meningkatkan pengetahuan petani, salah satunya adalah dengan membangun sistem pengetahuan yang dapat mengelola pengetahuan ubi jalar sehingga dapat digunakan oleh petani ubi jalar dalam memahami bagaimana budidaya ubi jalar yang tepat. Karena bila tidak ada knowledge management, maka pengalaman-pengalaman, dan ilmu-ilmu yang telah di dapat oleh orang-orang sebelumnya, maka akan terbawa dan hilang begitu saja, seiring menghilangnya orang yang tergantikan tersebut. Apabila pengetahuan yang dimiliki oleh seseorang tidak didokumentasikan, maka ketika orang tersebut telah habis masa jabatannya, maka penggantinya harus mengalami proses dari 0 (nol) lagi, semisal, mengumpulkan pengalaman-pengalaman dari nol, atau harus mengalami training yang sama dengan seniornya terdahulu, yang mana pasti memakan biaya dan dari segi waktu kurang effisien, Karena Itulan tercipta sebuah sistem yang sering dikenal manajemen pengetahuan, atau dengan istilah knowledge management system life Cycle (KMSLC) yang disebut juga siklus hidup sistem manajemen pengetahuan dan merupakan salah satu metode pengembangan didalam sistem manajemen pengetahuan.

\section{Metode}

\subsection{Knowledge}

Pengetahuan (Knowledge) adalah sebuah perpaduan dari rumusan pengetahuan, nilai, konteks informasi dan pengetahuan yang mendalam dari ahli yang menyediakan sebuah kerangka 
untuk mengevaluasi dan menggabungkan pengalaman dan informasi baru [3]. Ada dua jenis pengetahuan yang harus di kelola yaitu : Tacit knowledge dan Explicit knowledge.

\subsection{Knowledge management system (KMS)}

Sistem manajemen Pengetahuan adalah penggunaan teknologi informasi modern untuk sistematisasi guna meningkatkan dan mempercepat pengelolaan pengetahuan di dalam dan antar organisasi Suatu sistem dikatakan sistem manajemen pengetahuan apabila sistem tersebut memiliki klasifikasi sebagai berikut [4].

a. Adanya sistem untuk menemukan pengetahuan.

b. Adanya sistem untuk menangkap pengetahuan.

c. Adanya sistem untuk berbagi pengetahuan.

d. Adanya sistem untuk apliksi pengetahuan.

Agar pengetahuan mudah untuk dikelola, dikembangkan dan disebarkan, maka pengetahuan harus dikonversi dari tasit ke tasit, eksplisit ke eksplisit, tasit ke eksplisit dan eksplisit ke tasit. Konversi pengetahuan tersebut dinamakan SECI Model.

\subsection{Knowledge management system Life Cycle}

Salah satu metode dalam pengembangan sistem manajemen pengetahuan adalah Knowledge Management System Life Cycle (KMSLC). Di dalam metode ini pembangunan system meliputi beberapa tahap yaitu menangkap pengetahuan, membuat, kodifikasi, pengujian dan pengembangan, berbagi pengetahuan dan transfer pengetahuan. Diperlukan tools untuk menangkap pengetahuan dari pakar [5]. Menangkap pengetahuan bukanlah tugas yang mudah. Untuk menangkap pengetahuan yang berada didalam kepala manusia sering digunakan metode wawancara. Wawancara dapat dikategorikan dalam tiga jenis, yaitu :

a. Terstruktur merupakan bentuk wawancara yang menggunakan pertanyaan menyediakan jawabannya. Contohnya "multiple chois questions" atau pilihan ganda.

b. Tidak terstruktur merupakan bentuk wawancara dengan pertanyaan yang tidak direncanaka atau pertanyaan spontan.

c. Semi terstruktur merupakan wawancara dengan bentuk jawaban yang telah disediakan, dengan cara bebas mengekspresikan jawabannya

Metodologi yang digunakan dalam penelitian ini menggunakan metodologi Knowledge Management System Life Cycle (KMSLC) [5]. Adapun tahapan dari metodologi ini dapat dilihat pada Gambar 1.

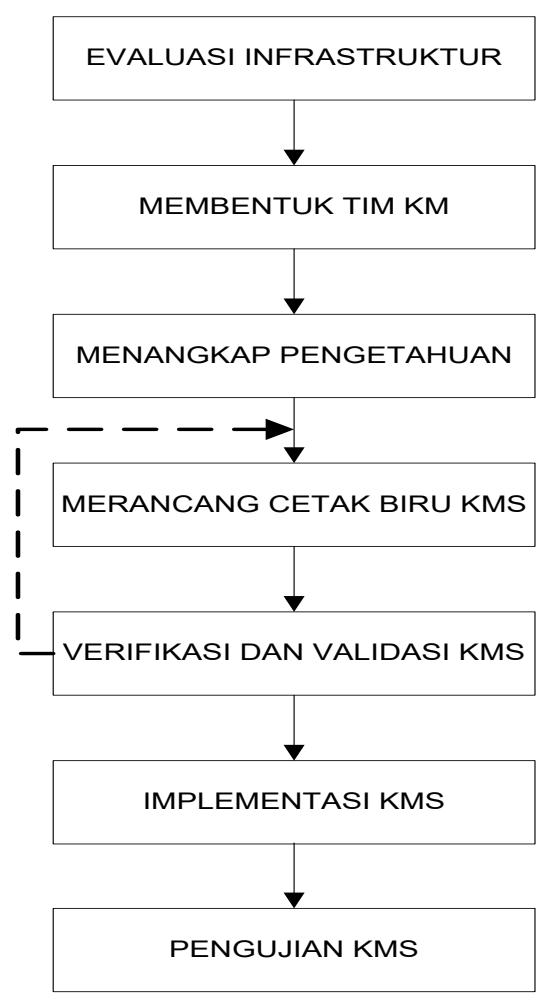

Gambar 1. Tahapan KMSLC 


\section{Hasil dan Pembahasan}

\subsection{Evaluasi Infrastruktur}

Pengetahuan yang dibutuhkan berdasarkan hasil wawancara dengan BP4K Kabupaten Keerom, diperoleh informasi bahwa untuk pengetahuan ubi jalar harus mengetahui : varietas unggul, tata cara budidaya ubi jalar secara benar dan terperinci, bagaimana penanganan hama dan penyakit ubi jalar [6]. Berdasarkan hasil analisa infrastruktur, maka sumber pengetahuan yang dimiliki memadai, yaitu adanya pakar, juknis dan buku dan teknologi yang dimiliki oleh BP4K, maka untuk pengelolaan pengetahuan dapat dibuat berbasis web.

\subsection{Membentuk Tim KM}

Setelah dilakukan evaluasi infrastruktur, maka dipilih dan dibentuk TIM knowledge management yang berperan untuk mengelola, mengembangkan dan menggunakan pengetahuan di dalam sistem.

a. Domain expert, atau pakar yang akan memberikan pengetahuan mengenai ubi jalar baik secara tasit maupun eksplisit adalah tim penyuluh dari BP4K, Dinas Pertanian, Balitkabi dan BP4K

b. Pengguna Akhir, yang dapat mengakses pengetahuan adalah petani ubi jalar khususnya petani dan user lainnya yang dapat mengakses sistem melalui web dan sms.

\subsection{Menangkap Pengetahuan}

Untuk merancang sebuah sistem, maka pengetahuan perlu dikumpulkan dan ditangkap. Ada beberapa metode untuk menangkap pengetahuan, metode yang dipilih untuk penelitian ini adalah wawancara, observasi dan studi pustaka mengenai tanaman ubi jalar. Tahap akhir pada proses ini akan diperoleh pengetahuan-pengetahuan yang diperlukan dalam budidaya pertanian ubi jalar.

\subsection{Merancangan Cetak Biru KMS}

Pengetahuan perlu ditangkap dari pakar agar dapat dikelola dan dikembangkan serta disebarkan kepada pihak-pihak yang membutuhkan. Pada penelitian ini teknik yang digunakan untuk menangkap pengetahuan adalah wawancara, observasi dan studi pustaka. Setelah pengetahuan diperoleh, rancang cetak biru KMS menggunakan frame. Frame digunakan untuk menyimpan pengetahuan yang bersifat deklaratif kemudian disajikan secara terperinci. Frame memiliki slot dan facet. Slot adalah set atribut yang mendeskripsikan objek yang direpresentasikan oleh frame. Facet digunakan untuk mendeskripsikan beberapa pengetahuan mengenai atribut dalam slot [7]. Dengan melihat karakteristik dari pengetahuan mengenai varietas, maka pengetahuan dapat direpresentasikan menggunakan frame sebagai berikut:

Tabel 1. Frame Varietas

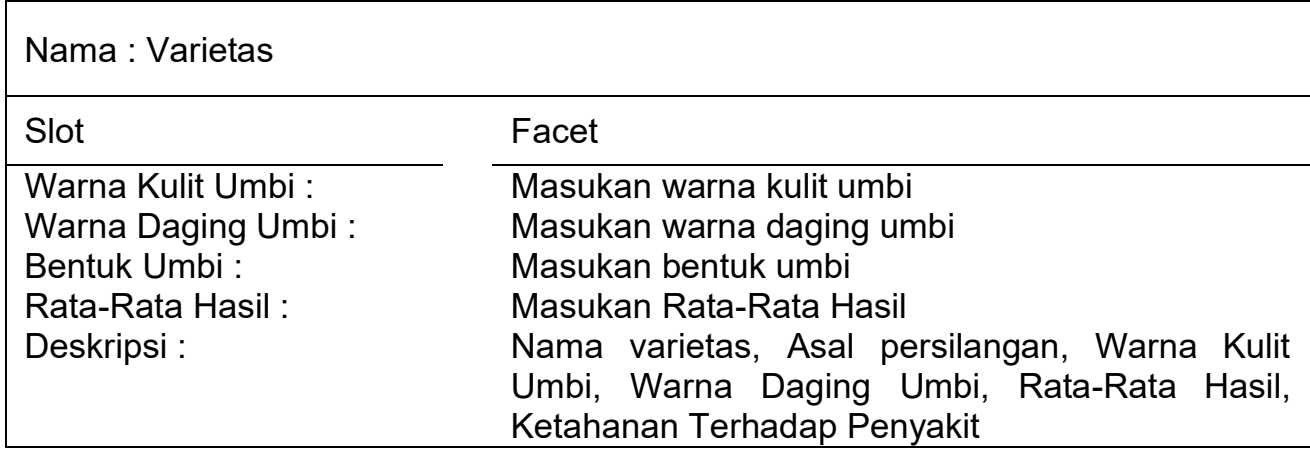

\subsection{Verifikasi dan Validasi KMS}

Verifikasi dan validasi KMS dilakukan untuk menghindari terjadinya keasalahan-kesalahan dalam sistem. Pengujian pada perangkat lunak perlu dilakukan sebelum sistem tersebut digunakan oleh para user. Tujuannya untuk mengetahui apakah fungsi-fungsi yang ada seperti input dan output telah sesuai dengan spesifikasi yang dibutuhkan. Pengujian tersebut dilakukan berupa mencoba semua fungsi yang ada dengan kasus benar dan salah.

\subsection{Implementasi KMS}

Pada tahap ini cetak biru KMS diimplementasikan ke dalam rancangan sistem menggunakan PHP dan MySQL serta tools lain yang mendukung perancangan sistem serta bisa mendownload dokumen tentang budidaya ubi jalar seperti yang terlihat pada gambar dibawah ini. 


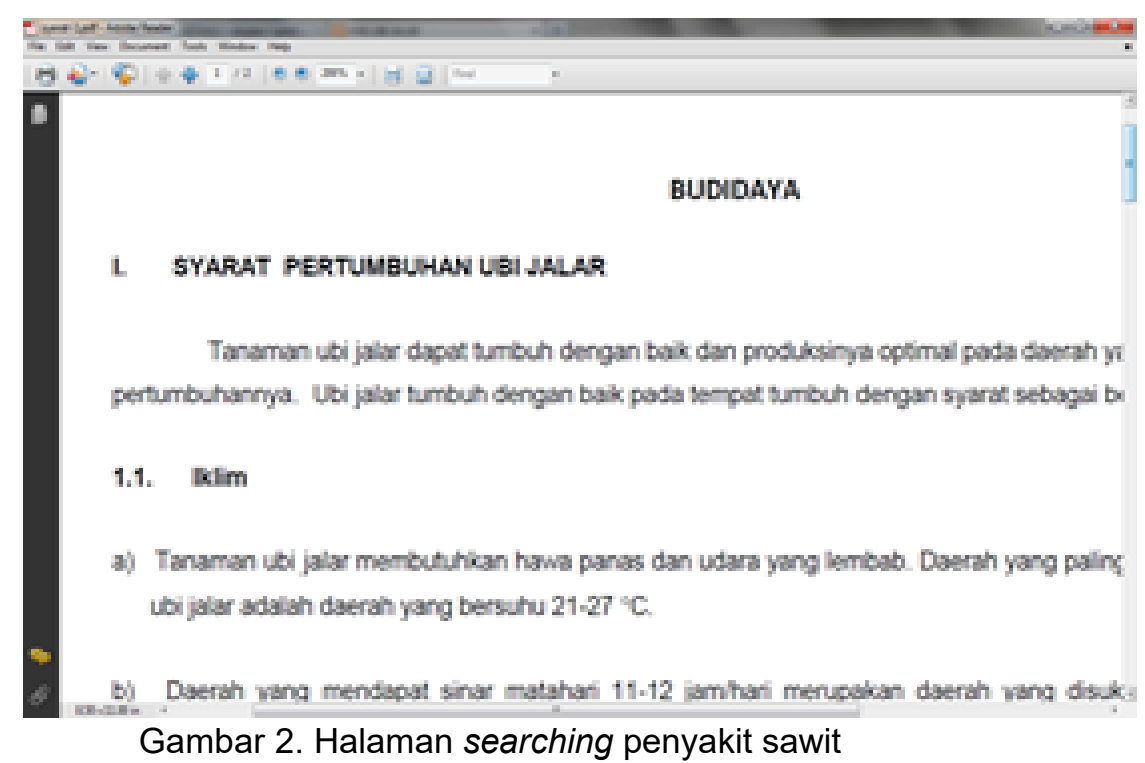

\subsection{Pengujian KMS}

Sistem yang telah dibangun harus diuji agar sistem yang dihasilkan sesuai dengan desain dan kebutuhan sistem. Adapun pengujian yang dilakukan menggunakan metode blackbox. Blackbox adalah pengujian sistem dengan melihat kesesuaian antara inbox dengan outbox, memastikan bahwa semua fungsi di dalam sistem telah berjalan dengan baik dan benar. Pengujian yang dilakukan dengan blackbox antara lain:

1. Apakah Admin dapat login ke sistem ? Ya

2. Apakah output yang dihasilkan telah sesuai dengan input yang dimasukan ke dalam sistem ? Ya

3. Ketika terjadi penambahan, update, dan hapus data apakah data pada database berubah ? Ya

4. Apakah semua tombol navigasi berjalan sesuai dengan fungsinya ? Ya

5. Apakah interface yang ditampilkan sesuai dengan menu yang dipilih ? Ya

6. Jika terjadi penyimpanan, perubahan maupun hapus data, apakah terdapat pesan konfirmasi ? Ya

7. Apakah sistem mudah digunakan ? Ya

8. Apakah pengguna dapat mendownload pengetahuan ? Ya

\section{Perancangan Kebutuhan Sistem}

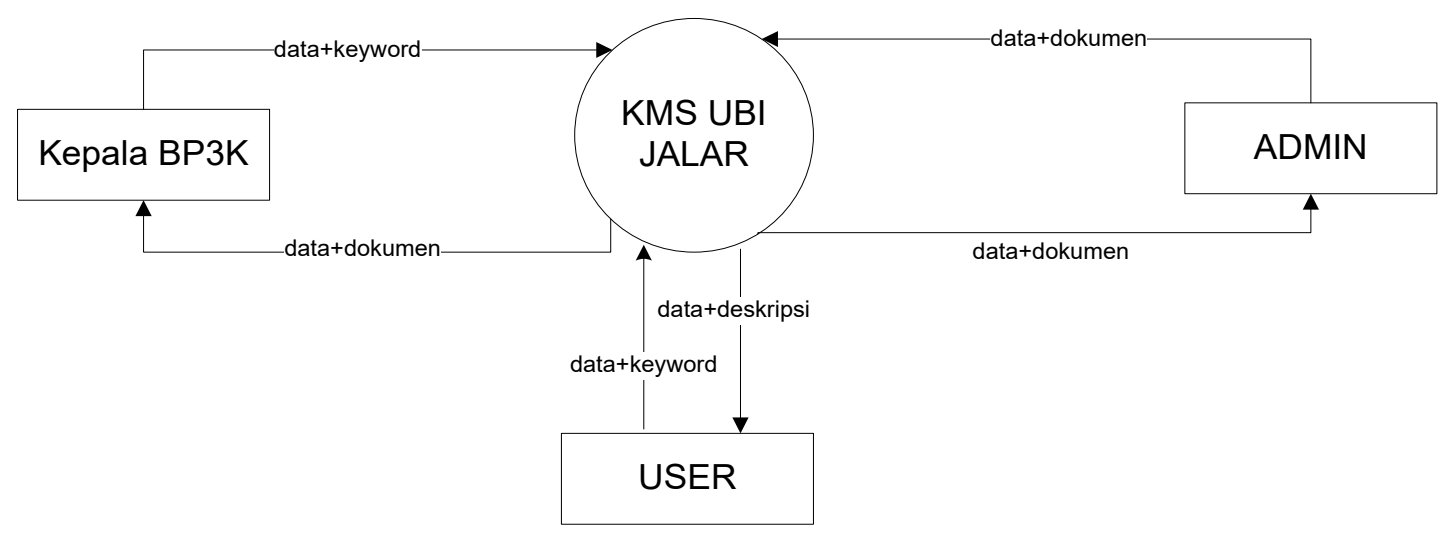

Gambar 3. Diagram Konteks KMS Ubi Jalar 


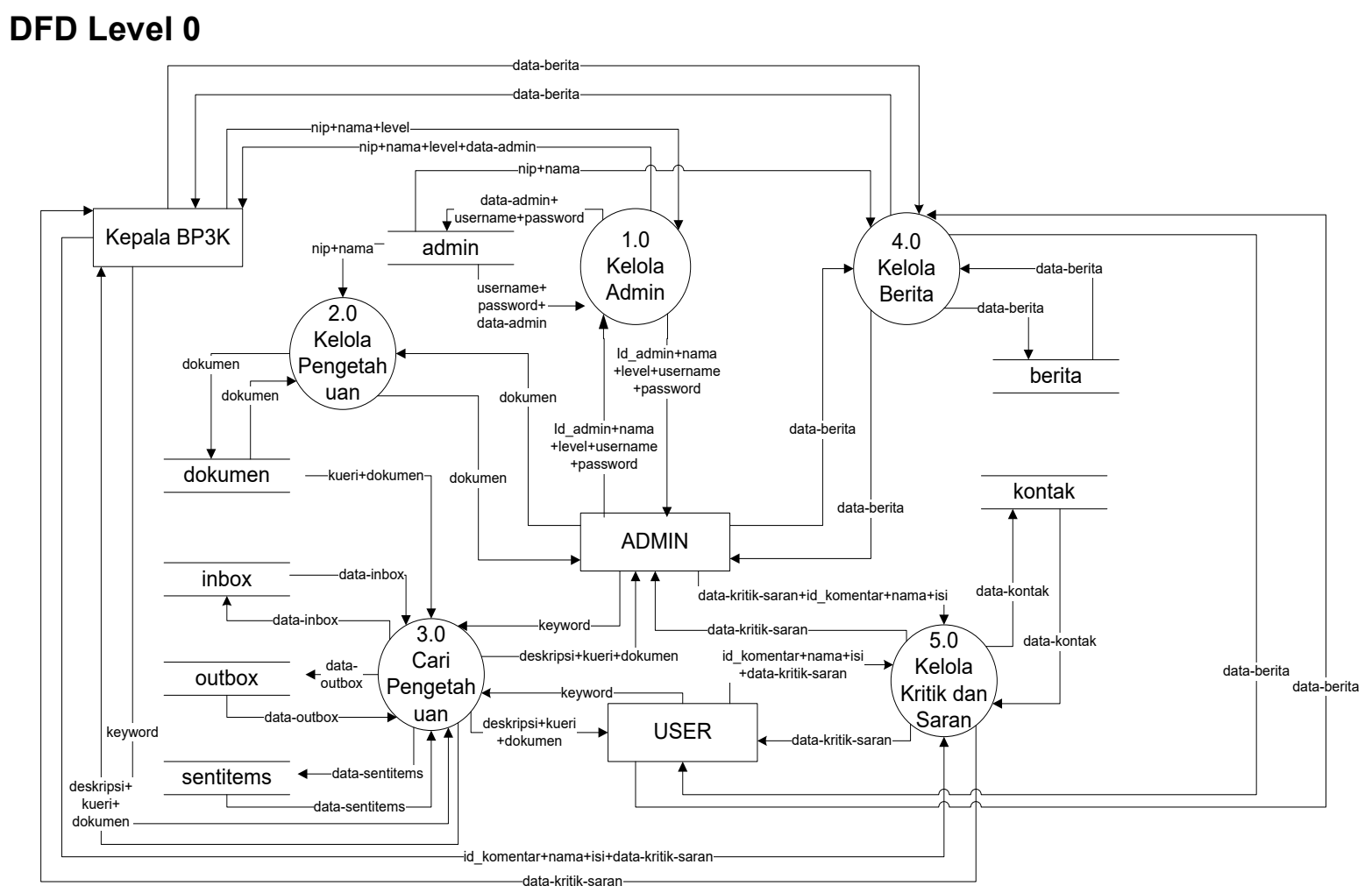

Gambar 4. DFD Level 0 KMS Ubi Jalar

\section{Entity Relationship Diagram (ERD)}

Berdasarkan DFD yang telah dirancang, maka dihasilkan tabel-tabel yang dibutuhkan oleh sistem. Untuk menggambarkan hubungan/relasi antar tabel digambarkan menggunakan Entity Relationship Diagram (ERD) yang dapat dilihat pada Gambar 5

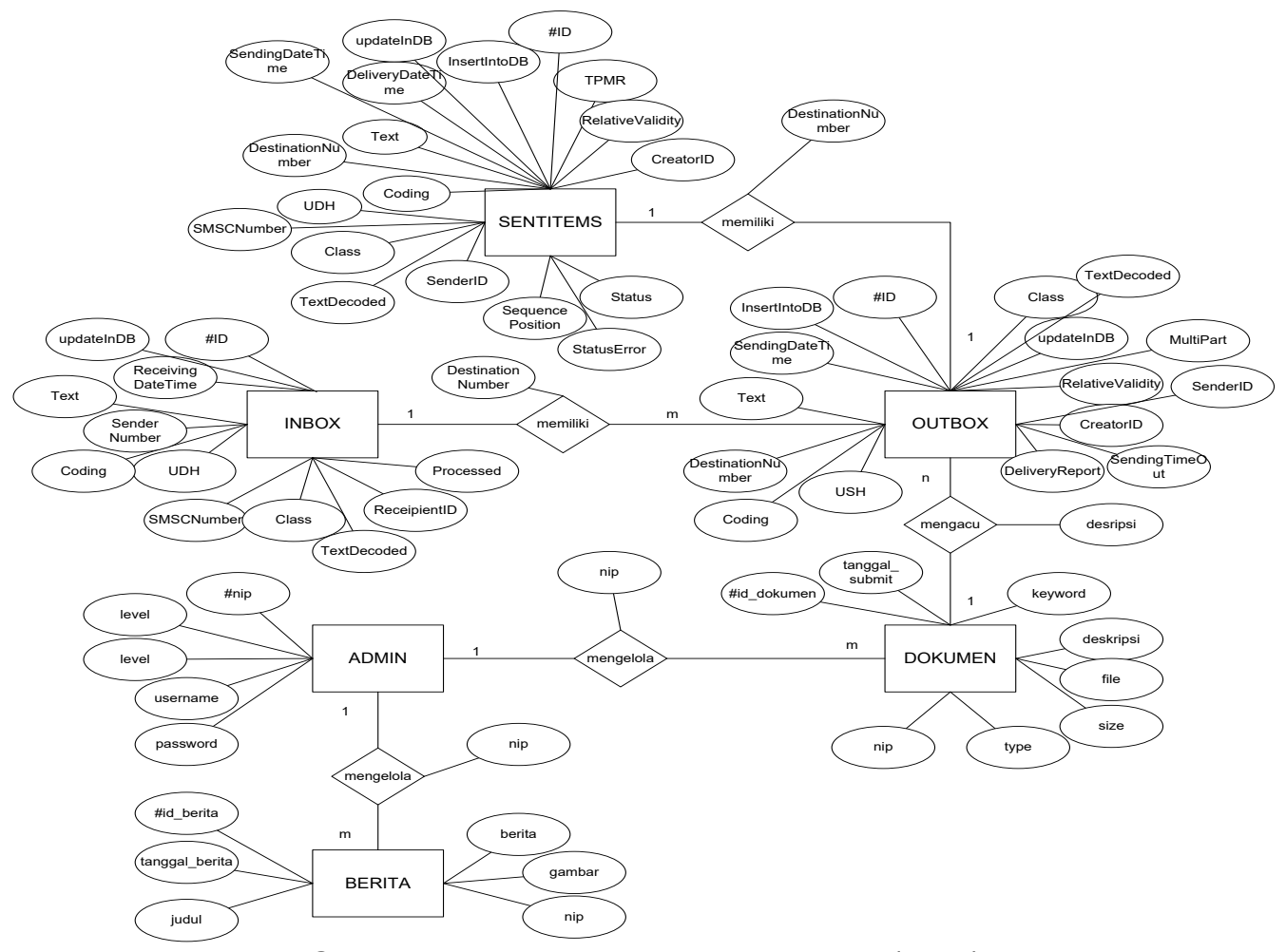

Gambar 5. Entity Relationship Diagram (ERD) 


\section{ILKOM Jurnal Ilmiah Volume 10 Nomor 1 April 2018}

\section{Tampilan Form Login Berbasis Web}

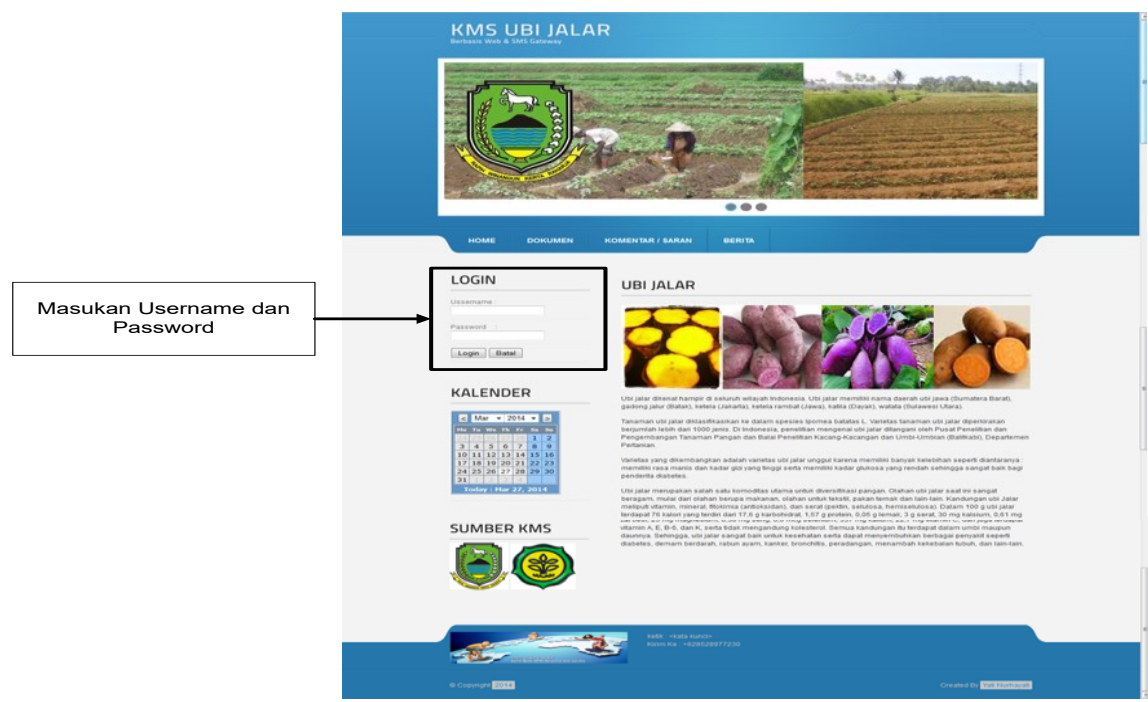

Gambar 6. Tampilan Form login

\section{Tampilan Input Dokumen}

\section{INPUT DOKUMEN}

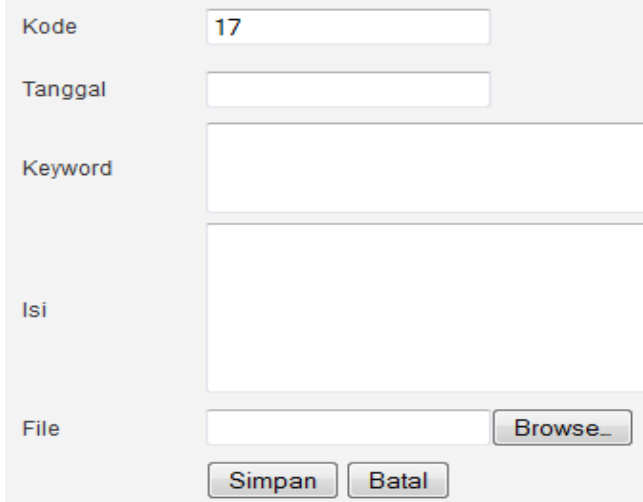

\section{Tampilan Detail Dokumen}

Gambar 7. Tampilan input dokumen

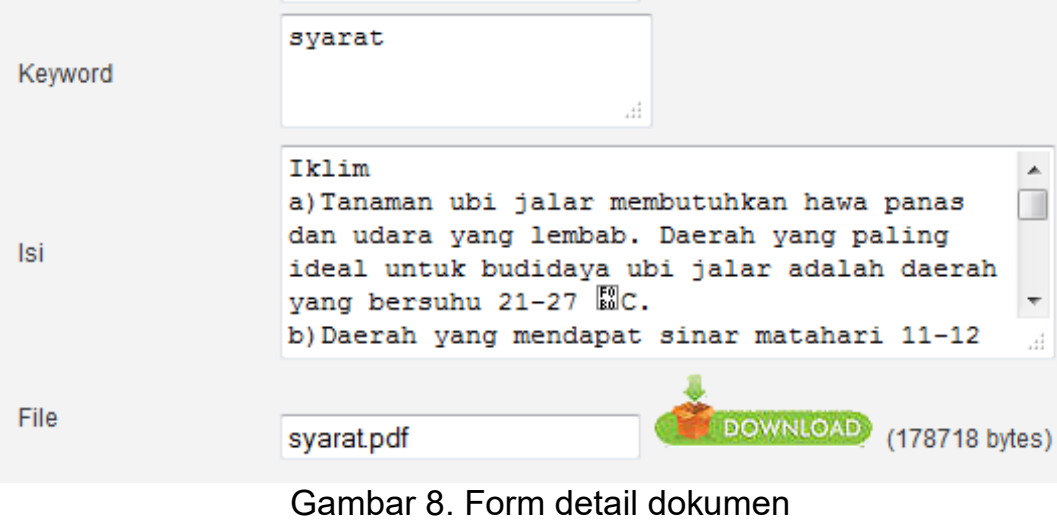




\section{Kesimpulan dan Saran}

Telah dibangun sistem manajemen pengetahuan ubi jalar, dimana pengetahuan ditangkap dari pakar melalui wawancara, observasi dan studi pustaka, serta direpresentasikan dengan menggunakan metode frame. Pengetahuan yang telah ditangkap dapat di download sehingga diharapkan dapat membantu penyuluh dalam transfer pengetahuan ke petani dan memudahkan petani untuk memperoleh pengetahuan mengenai budidaya ubi jalar yang tepat, Karena pengetahuan memiliki sifat yang selalu berubah sesuai dengan perkembangan, maka pengetahuan harus rutin dilakukan maintenance oleh pakar, agar pengetahuan yang dihasilkan selalu up to date dan terjaga kevalidasiannya dan keakuratannya. Teknologi selalu berkembang, begitu pula pengguna teknologi, oleh karena itu sebaiknya untuk penelitian selanjutnya, media transfer pengetahuan harus dikembangkan dan disesuaikan dengan perkembangan teknologi yang dimiliki dan dikuasai oleh petani

\section{Daftar Pustaka}

[1] Kubelaburbir, H. 2010. Zona Agroekologi Kabupaten Keerom Provinsi Papua Berdasarkan Pendekatan Sistem Informasi Geografis (GIS). Jurnal Agrikultura. Vol. 21. No. 1. Jakarta

[2] Rukmana, R. 2014. Ubi Jalar Budidaya dan Pascapanen, Kanisius, Jogyakarta Inc.

[3] Tseng, S. 2013. The effects of information technology on knowledge management systems Expert Syst. International journal on computer science and engineering. Vol. 4 No. 4. Jepang.

[4] Awad, E.M dan Ghaziri, H.M. 2012. knowledge Management. International Technology Group. 129-142. Virginia.

[5] Fernandes, B. 2013. Knowledge management System and process. International journal on computer science and engineering. Vol. 3 No. 4. London, Sabherwal.

[6] [Dirbun] Direktorat Jenderal Perkebunan. 2014. Badan Pelaksanaan Penyuluhan Pertanian, Perikanan dan Kehutanan, Direktorat jenderal perkebunan, kementerian pertanian. BP3K. Jakarta.

[7] Claire, M. 2014. Knowledge Management and thedynamic nature of knowledge. Journal of the American Society for Information Science and Technology. Vol. 53. Issue 12.1009-1018 Amerika. 